\title{
Unconventional Substance Use among Young People in Urban Lagos and the Implications for Sexual and Reproductive Health
}

\author{
Onipede Wusu; R.A. Soniyi; Z.A. Kazeem; \\ R.Y. Abogunloko; A.R. Animashaun \\ O.M. Balogun; B.E. Ajibade; J.O. Otike; \\ O.M. Adeoye
}

Department of Sociology

Lagos State University, Lagos, Nigeria

\begin{abstract}
Previous studies have examined conventional substance use among young people but little is known about unconventional substance use in this population. Hence, this study sought to explore unconventional substance use among young people in urban Lagos and the implications for sexual and reproductive health (SRH). The study employed cluster sampling strategy in administering 1200 copies of a structured questionnaire among in-school and out-of-school young people (10-24 years old) across selected areas in urban Lagos. Results indicated that the social environment of young people influenced their involvement in unconventional substance use $(p<0.05)$ in the study setting. Older young people, those out-of-school, exposure to unconventional substance use through peers, through television and those less religious were more likely to report ever use of any unconventional substance. Tramadol, cough syrup, and rohypnol were the most popular unconventional substances ever used among both male and female respondents. Also, while young females who used various unconventional substances were vulnerable to STIs owing to poor preventive behaviour, multiple sexual partnership was rampant among their male counterparts though rich preventive culture prevailed among them. Thus, unconventional drug use among young people has a strong probability of increasing health burden through risky $S R H$ in the study setting.
\end{abstract}

Keywords: Urban Lagos, unconventional substance use, sexual and reproductive health

\section{Introduction}

The socio-economic development of any human society is in the hands of its younger generation. Quality training of the minds of the younger generation is key to availability of quality human capital to drive productive activities. Thus, quality human capital is the bedrock of sustainable socio-economic development. How does young people's substance use (subsequently used interchangeably with drug use) compromise growing quality human capital to provide for this bedrock?

Drug use has been of interest to social and allied researchers for decades, maybe because of the devastating implications for society. Most of previous 
studies have focused on conventional substance use among young people, but little is known about unconventional substances in this population. Also, most of the studies that have investigated drug or substance use globally took place in the developed societies (Stockings et al., 2016). Thus, majority of the evidence available on drug use are foreign, knowledge about the behaviour in developing societies, where circumstances prevailing might promote it, is limited (Osman et al., 2016). Hence, this study that examined unconventional substance use in a typical developing society is apposite. In the context of this study, unconventional drugs include substances outside the public knowledge of wrong drugs. Such substances include tramadol, cough syrup, rohypnol, mixture, methylated spirit, septic tank, human dung, and petrol.

Evidence supports the fact that substance use remains a significant problem among young people globally (Olumide et al., 2014). Young people aged 1519 years and youth up to 24 years of age have been identified as being particularly vulnerable (Butler, Sindicich, and Burns, 2014; Degenhardt, Stockings, Patton, Hall and Lynskey, 2016; Osman et al., 2016). Some of the factors that single out young people in substance use (mostly conventional ones) include curiosity, being out-of-school, parental drug use, peer influence, sex, absence of father figure, self-concept, and aggressive acting behaviour (Haase and Pratschke, 2010; Olumide et al., 2014; Dada, Odukoya and Okuyemi, 2016; Osman et al., 2016). This study examined some of these factors but sought to contribute to our understanding of substance use among young people by looking at some factors that have not been focused upon and that are peculiar to a typical developing context. Critical among such factors are religiosity, frequency of interaction with parents, and means of exposure to drugs.

Previous studies have reported various harms of drug use in society, mostly in advanced countries (Macleod et al., 2004; Hall et al., 2016; Stockings et al., 2016). Of interest in this study is the implications of drug use for SRH burden among young people. A significant challenge has been inconsistencies in the findings of various studies that have sought to relate drug use and indicators of SRH (Schantz, 2012; Jackson et al., 2016). The inconsistencies in the findings of such studies suggests the need for further studies. To start with, a 2013 study ascribed $14 \%$ of total health burden to alcohol and illicit drug use among men 20-24 years of age, which underscores the significance of paying attention to unconventional drug use among young people (Degenhardt et al., 2016).

Many studies have reported that drug use among young people is associated with risky sexual behaviour (Graves and Leigh, 1995; Doku, 2012; Baldwin, Shrestha, Potrepka and Copenhaver, 2013; Nwagu, 2015) and sex under influence of drugs (Calsyn et al., 2010; Wells, Kelly, Rendina and Parsons, 2015). Other sexual and reproductive health indicators significantly associated with drug use that have been reported include multiple sexual relationship (Graves and Leigh, 1995; Doku, 2012; Pillon, O'Brien and Chavez, 2005; Khadr et al., 2016), unprotected sex and risk of sexually transmitted infections (STIs) (Calsyn et al., 2010; Reid, Hammond, McCrory, Dubin and 
Leatherdale, 2015; Wells et al., 2015; Khadr et al., 2016; Janulis, Feinstein, Phillips, Newcomb and Brain, 2018).

Three questions are critical to this study. First, what is the prevalence of unconventional drug use among young people in developing societies, for instance, in this study population? Second, what are the predictors of unconventional substance use among young persons in a less developed context such as in Lagos metropolis? Third, what is the nature of the association between unconventional substance use and SRH indicators in a less developed setting such as Lagos metropolis? Similarly, three objectives guided the study: prevalence of emerging unconventional drugs among young people aged 10-24 years in urban Lagos; the predictors of unconventional drug use among young people; and the implications of unconventional drug use for SRH indicators among young people in urban Lagos.

\section{Theoretical/Conceptual Framework}

The conceptual framework of this study is predicated upon the social learning theory and the theory of differential association. The social learning theory posits that most human behaviour are learnt through observation, imitation, and modelling (Bandura, 1977). Albert Bandura articulated that people learn from one another by observing the behaviours, attitudes, and outcomes of others. The theorist explained that people pick up new behaviours as they observe others, then generate an image about how such behaviours are performed and eventually see such behaviours as guides for their actions. According to Bandura, four conditions necessitate the social learning process. The conditions include the distinctive behaviour that attract individuals' attention, which they can internalise and eventually reproduce, and that they are motivated by the reward or punishment such behaviour attracts (Bandura, 1977).

However, it is not all behaviours adopted that are attractive to the individuals learning them. Hence, the theory of differential association developed by Edwin H. Sutherland is used to compliment the social learning theory. The differential association theory posits that delinquent behaviours are learned through over-exposure to individuals who are given to such behaviour (Cressey, 1952; Sutherland, 1947). Theory of differential association says that people learn delinquent or criminal behaviours and the techniques as they are exposed to behaviours of others that appear to legitimise such delinquent acts (Cressey, 1952). The theory explains that the attitudes and motives consistent with criminal activities are transferred through contact with individuals involved in such activities (McCarthy, 1996).

Therefore, young people get to learn about various unconventional substances from one another through over-exposure to the behaviour of those who are given to it or come in contact with such individuals. They learn about unconventional drugs as they observe the behaviour of their peers or others who indulge in such behaviours that they come in contact with in their social environment. When drug use becomes attractive to such learners, they may retain and could reproduce such behaviour copied from their models, when the 
situation presents itself. The reproduction of unconventional drug use as observed in models who they come in contact with frequently, is usually facilitated by the motivations derived from the perceived benefits (or punishments) their models receive. Also, the attitude and motives communicated by such models could drive adoption of unconventional substance by learners. As a result, as illustrated in Figure 1, the social environment where unconventional drug use models are presented to young people may include the families, peer associations, religious organisations, schools, residential areas, and media.

Similarly, the SRH behaviour that are presented by their unconventional drug use models may appear to young people as benefits for their drug use behaviour. SRH could be components of the attitudes transferred to the young learners by those who are given to such drugs as the learners interact with them. Therefore, the learning young persons are motivated to adopt such SRH behaviour. It is the interconnections among social learning, drug use, and SRH indicators that formed the focus of this study. Also, the nature of social environment and available motivations as well as attitudes communicated by drug users could directly influence SRH positively or negatively. This study therefore tested the hypothesis that the social environment of young people is likely to influence their involvement in unconventional drug use in urban Lagos. 


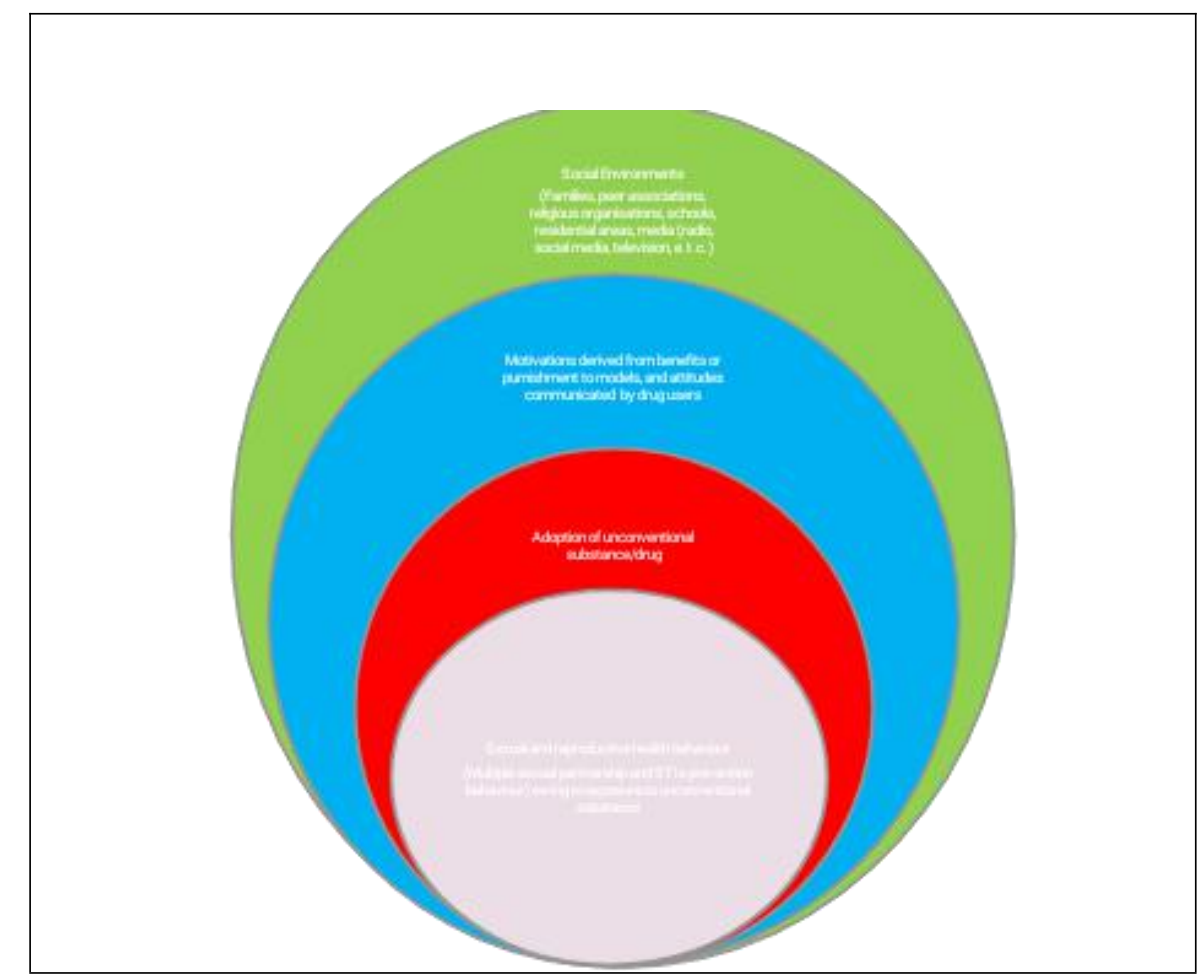

Source: Wusu et al. (2019)

Fig. 1: Unconventional substance/drug use in social learning and differential association contexts framework

\section{Data and Methods}

\section{Sampling}

This study used primary data collected among young people between 10 and 24 years of age. The focus on the age group was predicated on the observation made by authors that drug use begins from very age (as low as 10 years old) through to the upper limit of young age. The study group conducted a survey in selected urban areas of Lagos State between June and August 2018 among 1200 young people but 1019 satisfied quality for analysis. For ethical reason, before the study commenced, the research group decided to obtain verbal consent from every potential respondent as the basis for inclusion in the study. Also, every potential respondent was at liberty to withdraw at any levels or could decide to stop answering questions in the instrument if he/she felt like doing so. Members of the study group, who conducted the survey, implemented this ethical decision while administering the survey instrument.

The survey employed cluster sampling strategy. First, the research team stratified the study population into in-school and out-of-school young persons. The study group, through acquaintance visit, identified areas that were notorious for drug activities among young people in Lagos metropolis and its 
urban environs. Through this process the researchers purposively selected Alimosho, urban Ikorodu, Oshodi, and Yaba because the study team awareness suggests that substance use is rampant in those areas. The research team successfully negotiated access to three public secondary schools in Alimosho and Ikorodu for in-school respondents. As a result, the survey instrument was administered to senior and junior secondary students who were willing to participate in the study. With the assistance of the teachers in the schools, the questions were explained to the students and got them to fill out the instrument. For the in-school segment (secondary schools) of the survey, the team administered 560 copies of the study questionnaire. Also, the study group randomly selected three tertiary institutions in the city and its environs, namely Adeniran Ogunsanya College of Education, University of Lagos, and Yaba College of Technology, to capture young people in tertiary institutions. In this segment, the research team administered 360 copies of the questionnaire on randomly selected young persons.

Through rigorous deliberations and informal investigations the researchers identified streets and hideouts in Oshodi and Yaba clusters where drug use was rampant. Although it was difficult to get young people to respond to the questions in these clusters, the research team made effort to explain the purpose of the research to the subjects and filled out the instrument for those who were willing to participate. This group of respondents included the adolescents (15-19 years of age) and the young adults (up to 24 years of age). On the selected streets, members of the research group administered the survey instrument on young people in the spots where they gather in the evenings for social interactions after obtaining approval from their leaders. The research group administered 280 copies of the questionnaire in this category of respondents. This category of respondents were out-of-school or had finished one school or the other, or undergoing part-time or full-time schooling.

\section{Measurement}

We measured unconventional drug use by asking two questions. First, 'have you ever used any of these substances?' and the responses were ' 1 . No' or 2. Yes'. Second, 'which of the following substances have you ever used?' Respondents were expected to indicate as many as applicable. We later recoded each of the nine drugs (tramadol, cough syrup, rohypnol, mixture, gum, spirit, septic tank, human dung, and petrol) as individual variables with two options, '1. No' and '2. Yes'. Note that because the first three of the drugs (tramadol, cough syrup, and rohypnol) are also used for medical purpose, we asked another question: 'what was your main reason for taking these substances?' The question was an open-ended one. So we had to recode the responses into two categories, namely '1. Medical purpose' and '2. Non-medical purpose'. In the analysis, we only used those who used the first three substances to feel high as drug use, which was taking the drugs for medical purpose.

The social and demographic characteristics measured in the survey involved in the analysis include age, schooling presently, religiosity, family 
type, frequency of interaction with mother/father, parent living together, and means of exposure to substance use. Age was measured as a ratio variable (open-ended). The categorical version used in univariate and bivariate analyses came out of the process of classification, which yielded 1. '10-14', 2. '15-19', 3. '20-24'. Schooling presently had two response categories-1. 'No', 2. 'Yes'. Religiosity was measured through participation in religious programmes: how often do you attend religious programmes in a week? The question had four response categories, namely 1.'Once', 2.'Twice', 3. 'Thrice', and 4.'Four or more times'. In the analysis, the response categories were collapsed into 1. 'Less religious' (from the first and second categories) and 2. 'More religious' (from the third and fourth categories). Frequency of interaction with mother/father was also measured in a similar vein, through the questions 'how often do you interact with your mother in a week?' and 'how often do you interact with your father in a week?' had four response categories (1. 'Once', 2. 'Twice', 3. 'Thrice', and 4. 'Four or more times'. In the analysis, the response categories were collapsed into two, namely 1.'Less often' (from the first and second categories) and 2. 'More often' (from third and categories). Moreover, the survey instrument contained a question on family type with three response categories (1. 'Monogamy', 2. 'Polygyny', and 3. 'Single parent'. The variable means of exposure to substance use 'had peer group', 'social media', 'radio', and 'television' with each having 1. 'No' and 2. 'Yes' as response categories.

The research team measured SRH through two indicators. The indicators include multiple sexual partnership and sexually transmitted infection (STI) prevention behaviour. For multiple sexual partnership, the survey instrument asked directly 'how many sexual partner(s) do you regularly engage in sexual acts?' The question was open ended, which was renamed multiple sexual partnership and recoded as ' 1 . No' meaning one or no sexual partner while ' 2 . Yes' represented having two or more sexual partners. We derived STI prevention behaviour from the question 'during your last sexual act, what form of protection did you use?' Use of condom was named STI prevention behaviour. Non-use of condom was named risky behaviour and coded ' 1 . No' while use of condom '2. Yes'.

\section{Analysis}

Data analysis was carried out by sex and followed the traditional three levels: univariate, bivariate, and multivariate analyses. In the univariate analysis, we presented the percentage distribution of respondents by selected cultural, social, and demographic characteristics as well as the unconventional drugs measured in the study. The bivariate level of analysis related the cultural, social, and demographic background of the respondents to ever use of any unconventional drugs. The bivariate level of analysis deployed the Chi-square statistical technique. Also, at bivariate level of analysis, we carried out percentage distribution of respondents by ever use of the identified unconventional drugs and the two SRH indicators (multiple sexual partnership and STI prevention)among those who ever had sex. Multivariate analysis examined the influence 
of cultural, social, and demographic factors on ever use of any unconventional drugs, use using the Logistic regression technique. At this level of analysis the dependent variable was unconventional drug use (coded 'No' $=0$ and 'Yes' = 1). The independent variables included in the models are age, religiosity, schooling presently, family type, parent living together, exposure to drug use through peer group, exposure to drug use through social media, exposure to drug use through television, and exposure to drug use through radio. We used the SPSS version 23.0 in the data analysis.

\section{Results}

Table 1 presents the cultural, demographic, and social background of the respondents. Majority of both males and females were within the 15-19 years age bracket while those within 10-14 constituted minority. Also, a vast majority of the respondents were more religious, schooling presently and never married. Moreover, most of them were from monogamous family background. Surprisingly, both male and female respondents followed same pattern of interaction with their parents. Majority of both categories of respondents interacted more often with their mothers and less often with their fathers. Same proportion of male and female respondents reported that both parents were living together.

Although majority of both categories of respondents indicated that they never consumed any unconventional substance, a quite significant proportion of male respondents (44.1\%) indicated ever consumed any of the unconventional drugs. In contrast, just $19.3 \%$ of females reported ever consuming any of the unconventional substances. Also, a vast majority of males and females (ranging between 59.4\% and 79.4\%) indicated peer groups, social media, and television) as means of exposure to unconventional drugs. Conversely, a slightly lower proportion indicated exposure to unconventional drugs through radio among females $(48.9 \%)$ but marginally higher among males $(50.1 \%)$. 
Table 1: Percentage distribution of respondents by selected characteristics

\begin{tabular}{|c|c|c|}
\hline Characteristics & Male $(n=478)$ & Female $(n=541)$ \\
\hline \multicolumn{3}{|l|}{ Age } \\
\hline $10-14$ & $8.8(42)$ & $14.2(77)$ \\
\hline $15-19$ & $69.5(332)$ & $74.9(405)$ \\
\hline $20-24$ & $21.8(104$ & $10.9(59)$ \\
\hline \multicolumn{3}{|l|}{ Religiosity } \\
\hline Less religious & $31.2(148)$ & $27.1(146)$ \\
\hline More religious & $68.8(326)$ & $72.9(393)$ \\
\hline \multicolumn{3}{|l|}{ Schooling presently } \\
\hline No & $7.8(36)$ & $4.3(23)$ \\
\hline Yes & $92.4(440)$ & $95.7(515)$ \\
\hline \multicolumn{3}{|l|}{ Marital status } \\
\hline Never married & $95.8(458)$ & $96.1(520)$ \\
\hline Ever married & $4.2(20)$ & $3.7(20)$ \\
\hline \multicolumn{3}{|l|}{ Family background } \\
\hline Monogamy & $58.1(272)$ & $60.2(318)$ \\
\hline Polygyny & 23.1(108) & 19.3(102) \\
\hline Single parenthood & $18.8(88)$ & $20.5(108)$ \\
\hline \multicolumn{3}{|l|}{$\begin{array}{l}\text { Frequency of interaction with } \\
\text { mother }\end{array}$} \\
\hline Often & $43.7(206)$ & $44.8(239)$ \\
\hline More often & $56.3(265)$ & $55.2(294)$ \\
\hline \multicolumn{3}{|l|}{ Frequency of interaction with father } \\
\hline Often & $61.7(284)$ & $68.4(360)$ \\
\hline More often & $38.3(176)$ & $31.6(166)$ \\
\hline \multicolumn{3}{|l|}{ Parents living together } \\
\hline No & $16.5(78)$ & $16.5(89)$ \\
\hline Yes & $83.5(396)$ & $83.5(449$ \\
\hline \multicolumn{3}{|l|}{ Ever use of any unconventional drug } \\
\hline No & $55.9(264)$ & $80.7(430)$ \\
\hline Yes & $44.1(208)$ & $19.3((103)$ \\
\hline \multicolumn{3}{|l|}{$\begin{array}{l}\text { Exposure to drug through peer } \\
\text { group }\end{array}$} \\
\hline No & $20.6(97)$ & $21.9(117)$ \\
\hline Yes & $79.4(375)$ & $78.1(418)$ \\
\hline \multicolumn{3}{|l|}{$\begin{array}{l}\text { Exposure to drug through social } \\
\text { media }\end{array}$} \\
\hline No & $28.8(135)$ & $29.2(155)$ \\
\hline Yes & $71.2(334)$ & $70.8(376)$ \\
\hline \multicolumn{3}{|l|}{ Exposure to drug through television } \\
\hline No & $39.1(182)$ & $40.6(213)$ \\
\hline Yes & $60.9(284)$ & $59.4(312)$ \\
\hline \multicolumn{3}{|l|}{ Exposure to drug through radio } \\
\hline No & $49.9(232)$ & $51.1(268)$ \\
\hline Yes & $50.1(233)$ & $48.9(256)$ \\
\hline
\end{tabular}

Note: differences in ' $n$ ' for the categories are due to variations in response rates 
In Table 2, the distribution of the respondents by the identified unconventional drugs are presented. The most common unconventional drugs were the ones that have medical uses. After deducting those who used the three drugs for medical reasons, tramadol, cough syrup and rohypnol the most popular drugs among the respondents. In particular, more than half of both male and female respondents reported ever using tramadol and cough syrup for purpose of feeling high. In the second category, mixture and gum were the second most popular drugs among the respondents. Over one fifth of males and $17.8 \%$ of females reported inhaling gum that shoemakers use in making shoes. Closer look at the practice of inhaling septic tank and fuel as well as smoking of human faeces/dung reveals that a slightly higher proportions of females reported ever consuming the three types of unconventional drugs compared to their male counterparts. Out of the nine unconventional drugs, inhaling septic tank and petrol, and smoking of human dung were the ones that females reported slightly higher prevalence than among males.

Table 2: Percentage distribution of respondents by ever use of various unconventional drugs

\begin{tabular}{|l|l|l|l|l|}
\hline Drug Type & \multicolumn{2}{l|}{ Male $(\mathbf{n}=\mathbf{4 7 8})$} & \multicolumn{2}{l|}{ Female (n= 541) } \\
\hline & $(\%$ Yes $)$ & Total & (\% Yes) & Total \\
\hline Tramadol & $74.0(94)$ & 127 & $70.9(39)$ & 55 \\
\hline Cough Syrup & $66.3(84)$ & 127 & $61.8(34)$ & 55 \\
\hline Rohypnol & $44.9(57)$ & 127 & $31.5(17)$ & 54 \\
\hline Mixture & $27.2(128)$ & 471 & $20.0(105)$ & 525 \\
\hline Gum & $20.3(95)$ & 467 & $17.8(93)$ & 523 \\
\hline Spirit & $17.9(84)$ & 470 & $16.6(88)$ & 523 \\
\hline Septic Tank & $14.1(66)$ & 467 & $15.5(81)$ & 523 \\
\hline Dung & $13.9(65)$ & 467 & $15.5(81)$ & 521 \\
\hline Petrol & $13.1(61)$ & 466 & $15.7(82)$ & 521 \\
\hline
\end{tabular}

Note: differences in ' $n$ ' for the categories is due to variations in response rates

Table 3 is presenting the bivariate association between selected cultural, demographic, and social variables and ever use of unconventional drugs among the respondents. Among male respondents, age, schooling status, religiosity, frequency of interaction with mother, and exposure to unconventional drugs through peer groups were significantly associated with ever use of any unconventional drugs. There was a positive association between age and ever use of any of the drugs $(p<0.01)$. The proportion that reported ever use of the drugs increased with higher age groups. Concerning present schooling status, higher proportion of male respondents who indicated not schooling presently reported ever use of any unconventional drugs than those schooling presently $(P<0.01)$.

Moreover, expectedly, males who were less religious reported higher prevalence of the drugs than those who indicated they were more religious $(p<0.001)$. The data also showed that male respondents who interacted more 
often with their mothers reported lower ever use of any unconventional drugs compared to those who interacted less often $(p<0.01)$. Also, higher proportion of males who indicated exposure to unconventional drugs through peers reported ever consuming any of the drugs $(p<0.01)$.

On the other hand, age $(p<0.001)$ and exposure to drugs through peers $(P<0.01)$ were significantly associated with ever use of any unconventional drugs among female respondents. Unlike the precise pattern of association observed between age and ever use of any drugs among males, the highest ever use was reported among females in the 20-24 years age bracket, followed by the 10-14 years age group while those in 15-19 years age group reported the least proportion. Conversely, a higher proportion of those who reported exposure to unconventional drugs through peers indicated ever consuming any of the drugs (22.2\%) compared to $9.6 \%$ among their counterparts not exposed through peers. 
Table 3: Percentage distribution of respondents by ever use of any unconventional drugs by selected social, cultural, and demographic factors, and by sex

\begin{tabular}{|c|c|c|c|c|}
\hline \multirow[t]{2}{*}{ Characteristics } & \multicolumn{2}{|c|}{ Male $(n=478)$} & \multicolumn{2}{|c|}{ Female $(n=541)$} \\
\hline & $\%$ Yes & Total & $\%$ Yes & Total \\
\hline \multicolumn{5}{|l|}{ Age } \\
\hline $10-14$ & $29.3(12)$ & 41 & $20.0(15)$ & 75 \\
\hline $15-19$ & $41.6(137)$ & 329 & $15.0(60)$ & 399 \\
\hline $20-24$ & $57.8(59)$ & 102 & $47.5(28)$ & 59 \\
\hline Chi-square & $12.3^{* *}$ & & $34.68 * * *$ & \\
\hline \multicolumn{5}{|c|}{ Schooling presently } \\
\hline No & $61.1(22)$ & 36 & $22.7(5)$ & 22 \\
\hline Yes & $42.9(186)$ & 434 & $19.1(97)$ & 502 \\
\hline Chi-square & $4.5^{* *}$ & & 0.2 & \\
\hline \multicolumn{5}{|l|}{ Religiosity } \\
\hline Less religious & $66.0(95)$ & 144 & $24.1(35)$ & 145 \\
\hline More religious & $34.0(110)$ & 324 & $17.4(67)$ & 386 \\
\hline Chi-square & $41.5^{* * *}$ & & 3.1 & \\
\hline \multicolumn{5}{|l|}{ Marital status } \\
\hline Never married & $43.7(198)$ & 453 & 19.1(98) & 513 \\
\hline Ever married & $52.6(10)$ & 19 & $26.3(5)$ & 19 \\
\hline Chi-square & 0.4 & & 0.4 & \\
\hline \multicolumn{5}{|c|}{ Family background } \\
\hline Monogamy & $40.4(109)$ & 270 & $17.7(56)$ & 316 \\
\hline Polygynous & $50.5(54)$ & 107 & $19.0(19)$ & 100 \\
\hline Single parenthood & $48.8(42)$ & 86 & $23.6(25)$ & 106 \\
\hline Chi-square & 4.0 & & 1.8 & \\
\hline \multicolumn{5}{|c|}{ Frequency of interaction with mother } \\
\hline Often & $50.2(103)$ & 205 & $22.1(52)$ & 235 \\
\hline More often & $40.0(104)$ & 260 & $17.5(51)$ & 291 \\
\hline Chi-square & $4.9^{* *}$ & & 1.7 & \\
\hline \multicolumn{5}{|c|}{ Frequency of interaction with father } \\
\hline Often & $45.7(128)$ & 280 & $20.6(73)$ & 355 \\
\hline More Often & $43.1(75)$ & 174 & $16.5(27)$ & 164 \\
\hline Chi-square & 0.3 & & 1.2 & \\
\hline \multicolumn{5}{|c|}{ Exposure to drug through peer group } \\
\hline No & $30.2(29)$ & 96 & $9.6(11)$ & 114 \\
\hline Yes & $47.4(176)$ & 371 & $22.2(92)$ & 414 \\
\hline Chi-square & $9.20 * *$ & & $9.00 * *$ & \\
\hline \multicolumn{5}{|c|}{ Exposure to drug through social media } \\
\hline No & $41.8(56)$ & 134 & $16.1(25)$ & 155 \\
\hline Yes & $44.4(147)$ & 331 & $20.5(76)$ & 370 \\
\hline Chi-square & 0.26 & & 0.37 & \\
\hline \multicolumn{5}{|c|}{ Exposure to drug through television } \\
\hline No & $29.1(70)$ & 179 & $16.5(35)$ & 212 \\
\hline Yes & 47.2(133) & 282 & $21.8(67)$ & 308 \\
\hline Chi-square & 2.88 & & 2.19 & \\
\hline \multicolumn{5}{|c|}{ Exposure to drug through radio } \\
\hline No & 43.2(99) & 229 & $21.7(58)$ & 267 \\
\hline Yes & $45.4(104)$ & 229 & $17.5(252)$ & 252 \\
\hline Chi-square & 1.81 & & 1.49 & \\
\hline
\end{tabular}

*Significant at $P<0.05, * *$ Significant at, $P<0.01, * *$ Significant at $P<0.001$. Note: differences in ' $n$ ' for the categories are due to variations in response rates 
The Odds ratios of the influence of cultural, demographic, and social factors on ever use of any unconventional drug use showed that age, religiosity, exposure to unconventional drugs through peers and television significantly predicted the dependent variables among males (see Table 4). There was positive association between age and ever use of any unconventional drugs $(P<0.05)$. Older young females were more likely to report ever use of any unconventional drugs than younger ones. Those who were more religious were less likely to have consumed any unconventional drugs relative those who were less religious $(P<0.001)$. Also, males who got exposed to drugs through peers and television were 1.96 times $(p<0.05)$ and 1.76 times $(p<0.05)$, respectively, more likely to report ever use of any unconventional drugs compared to those not exposed through peers or television.

On the other hand, among female respondents, age, exposure to drugs through peers and television significantly predicted ever use of unconventional substance. Similar to males, age was positively related to ever consumption of unconventional substance among females $(p<0.001)$. Older females were more likely to report ever use of any unconventional drugs than those relatively younger. Moreover, those exposed to drugs through peers were over twice more likely to indicate ever using any drugs than those not exposed through peers $(p<0.05)$. Similarly, those exposed to unconventional drugs through television were almost twice more likely to report ever use of any unconventional drugs than those who did not get exposed through television $(p<0.05)$. 
Table 4: Odds Ratios (with 95\% CI) of Logistic regression on influence of cultural and socio-demographic characteristics on unconventional drug use among young people in urban Lagos by sex

\begin{tabular}{|c|c|c|}
\hline \multirow[t]{2}{*}{ Characteristics } & \multicolumn{2}{|c|}{ Odds Ratios } \\
\hline & Male & Female \\
\hline Age & $1.11(1.01-1.21)^{*}$ & $1.25(1.13-1.38)^{* * *}$ \\
\hline \multicolumn{3}{|l|}{ Religiosity } \\
\hline Less religious $(\mathrm{r})$ & - & - \\
\hline More religious & $0.30(0.19-0.48)^{* * *}$ & $0.78(0.47-1.31)$ \\
\hline \multicolumn{3}{|l|}{ Schooling } \\
\hline No (r) & - & - \\
\hline Yes & $0.79(0.36-1.71)$ & $1.26(0.41-3.83)$ \\
\hline \multicolumn{3}{|l|}{ Family type } \\
\hline Monogamy (r) & - & - \\
\hline Polygynous & $1.53(0.89-2.53)$ & $1.17(0.60-2.26)$ \\
\hline Single parent & $1.73(0.92-3.11)$ & $1.56(0.82-2.98)$ \\
\hline \multicolumn{3}{|c|}{ Parents living together } \\
\hline No $(r)$ & - & $-\quad-$ \\
\hline Yes & $1.70(0.94-3.16)$ & $1.06(0.54-2.89)$ \\
\hline \multicolumn{3}{|c|}{$\begin{array}{l}\text { Frequency of interaction with } \\
\text { mother }\end{array}$} \\
\hline Less often(r) & - & - \\
\hline More often & $0.69(0.43-1.12)$ & $0.89(0.53-1.49)$ \\
\hline \multicolumn{3}{|c|}{$\begin{array}{l}\text { Drug knowledge through peer } \\
\text { group }\end{array}$} \\
\hline No (r) & - & - \\
\hline Yes & $1.96(1.11-3.22)^{*}$ & $2.15(1.04-4.45)^{*}$ \\
\hline \multicolumn{3}{|c|}{$\begin{array}{l}\text { Drug knowledge through social } \\
\text { media }\end{array}$} \\
\hline $\mathrm{No}(\mathrm{r})$ & - & \\
\hline Yes & $0.79(0.46-1.35)$ & $0.83(0.45-1.54)$ \\
\hline \multicolumn{3}{|c|}{$\begin{array}{l}\begin{array}{l}\text { Drug knowledge through } \\
\text { television }\end{array} \\
\end{array}$} \\
\hline $\mathrm{No}(\mathrm{r})$ & - & - \\
\hline Yes & $1.76(1.05-2.2 .96)^{*}$ & $1.90(0.04-3.46)^{*}$ \\
\hline \multicolumn{3}{|c|}{$\begin{array}{l}\text { Frequency of interaction with } \\
\text { father }\end{array}$} \\
\hline $\mathrm{No}(\mathrm{r})$ & - & - \\
\hline Yes & $1.27(0.78-2.05)$ & $0.88(0.50-1.57)$ \\
\hline \multicolumn{3}{|c|}{ Drug knowledge through radio } \\
\hline $\mathrm{No}(\mathrm{r})$ & - & \\
\hline Yes & $0.91(0.69-1.19)$ & $0.58(0.33-1.02)$ \\
\hline Model Chi-square & $67.47 * * *$ & $40.04 * * *$ \\
\hline $\mathrm{N}$ & 427 & 484 \\
\hline
\end{tabular}

*Significant at $P<0.05, * *$ Significant at, $P<0.01, * *$ Significant at $P<0.001$ 
Table 5 presents the results on the implications of ever use of any of the unconventional drugs for SRH indicators. In the first instance, majority of male respondents who reported they ever used any of the unconventional drugs indicated having multiple sexual partners $(54.3 \%)$ and adoption of STIs prevention strategy (69.8) compared to their counterparts who never used any unconventional substance. Conversely, among female respondents, more of those who ever used drugs reported lower prevalence of multiple sexual partnership (14.7\%), but lower proportions reported adoption of STIs prevention $(38.5 \%)$ relative those who never used the drugs.

Also, the table shows the descriptive association between each of the drugs and the indicators of SRH. Among male respondents, higher proportion, ranging between mixtures $(59.0 \%)$ and inhaling septic tank $(74.1 \%)$ of those who ever used the substances reported having multiple sexual partners. However, a vast majority of those who ever used any of the unconventional drugs identified reported adoption of STIs prevention behaviour. The proportions varied between $65.7 \%$ (to inhale petrol) and $78.4 \%$ (use of tramadol). Among their female counterparts, the proportion of those who responded to the question on the SRH behaviour indicators were small across all the unconventional drugs. We observed that, across all the unconventional drugs, a lower proportion of those who reported ever use of the drugs indicated involvement in multiple sexual partnership, adoption of STIs and unwanted pregnancy prevention behaviour. With the exception of use of spirit and inhaling septic tank, where equal proportions of those who ever used $(50 \%)$ and never used (50\%) reported practicing multiple sexual partnership, between $23.5 \%$ (tramadol) and $44.4 \%$ (use of rohypnol) of those who ever used the drugs reported multiple sexual partnership compared to their counterparts who never used the drugs. Among those who reported adoption of preventing STIs, lower proportion of those who used the drugs reported the adoption of the preventive strategy relative those who never used. 
Table 5: Percentage distribution of respondents by unconventional drug use and sexual and reproductive health by sex among young people in urban Lagos

\begin{tabular}{|l|l|l|l|l|}
\hline \multirow{2}{*}{$\begin{array}{l}\text { Ever used any } \\
\text { (yes) }\end{array}$} & \multicolumn{2}{|c|}{ Male } & \multicolumn{2}{c|}{ Female } \\
\cline { 2 - 5 } & $\begin{array}{l}\text { Multiple } \\
\text { sexual } \\
\text { partnership } \\
\text { (yes) }\end{array}$ & $\begin{array}{l}\text { STIs } \\
\text { prevention } \\
\text { (yes) }\end{array}$ & $\begin{array}{l}\text { Multiple } \\
\text { sexual } \\
\text { partnership } \\
\text { (yes) }\end{array}$ & $\begin{array}{l}\text { STIs } \\
\text { prevention } \\
\text { (yes) }\end{array}$ \\
\hline Ever use of any drugs & $\mathrm{n}=138$ & $\mathrm{n}=150$ & $\mathrm{n}=34$ & $\mathrm{n}=39$ \\
& $54.3(75)$ & $70.0(105)$ & $14.7(5)$ & $38.5(15)$ \\
\hline Tramadol & $\mathrm{n}=74$ & $\mathrm{n}=74$ & $\mathrm{n}=17$ & $\mathrm{n}=18$ \\
& $60.3(44)$ & $78.4(58)$ & $23.5(4)$ & $44.4(8)$ \\
\hline Cough syrup & $\mathrm{n}=68$ & $\mathrm{n}=68$ & $\mathrm{n}=15$ & $\mathrm{n}=16$ \\
& $60.3(41)$ & $77.9(53)$ & $26.7(4)$ & $43.8(7)$ \\
\hline Rohypnol & $\mathrm{n}=47$ & $\mathrm{n}=47$ & $\mathrm{n}=9$ & $\mathrm{n}=10$ \\
& $63.8(30)$ & $72.3(34)$ & $44.4(4)$ & $30.0(3)$ \\
\hline Mixture & $\mathrm{n}=78$ & $\mathrm{n}=85$ & $\mathrm{n}=18$ & $\mathrm{n}=21$ \\
& $59.0(46)$ & $68.2(58)$ & $33.3(3)$ & $38.1(8)$ \\
\hline Gum & $\mathrm{n}=55$ & $\mathrm{n}=63$ & $\mathrm{n}=9$ & $\mathrm{n}=12$ \\
& $61.8(34)$ & $69.8(44)$ & $33.3(3)$ & $33.3(4)$ \\
\hline Spirit & $\mathrm{n}=42$ & $\mathrm{n}=48$ & $\mathrm{n}=6$ & $\mathrm{n}=9$ \\
& 61.9 & $70.8(34)$ & $50.0(3)$ & $33.3(3)$ \\
\hline Septic tank & $\mathrm{n}=27$ & $\mathrm{n}=33$ & $\mathrm{n}=4$ & $\mathrm{n}=7$ \\
& $74.1(20)$ & $66.7(22)$ & $50.0(2)$ & $28.6(2)$ \\
\hline Dung & $\mathrm{n}=28$ & $\mathrm{n}=34$ & $\mathrm{n}=5$ & $\mathrm{n}=8$ \\
& $60.7(17)$ & $70.6(24)$ & $40.0(2)$ & $37.5(3)$ \\
\hline Petrol & $\mathrm{n}=29$ & $\mathrm{n}=35$ & $\mathrm{n}=5$ & $\mathrm{n}=8$ \\
& $69.0(20)$ & $65.7(23)$ & $40.0(2)$ & $37.5(3)$ \\
\hline
\end{tabular}

\section{Discussion}

This study has examined the prevalence of identified unconventional substances among the young people aged 10-24 years in urban Lagos. Other issues addressed include the predictors of ever use of any of the substances and the implications of the use of such substances for SRH behaviour in the study population. The results suggest that out of the nine unconventional drugs, tramadol, cough syrup, and rohypnol were very popular amongst male and female respondents. These are drugs also used for medical reasons. Thus, the high prevalence of the three drugs indicates abuse of prescription drugs. The proportion that indicated use was higher among males than females. Substances such as inhaling septic tank and petrol, and smoking human dung, which one could consider horrible for human consumption, were relatively higher among female respondents. This observation is surprising but it may be plausible to explain the behaviour regarding the fact that it is not necessary to visit joints to use the three inhalants. Also, many young females may indulge in the three drugs indoor without their parents suspecting them. 
Bivariate analysis indicated that age, frequency of interaction with mother, religiosity, present schooling status and exposure to unconventional drugs through peers were significantly associated with ever use of any of the drugs among males. Among their female counterparts, age and exposure to drugs through peers were significantly related to ever use of any of the unconventional drugs. Although the bivariate association between age and ever use of drug did not present any clear pattern among female respondents, there was vivid positive association among males. Moreover, in the Logistic regression models, age significantly predicted ever use of any unconventional substance among male and female respondents. In contrast to what Butler and colleagues observed that drug use was highest among 15-19 years old (Butler et al., 2014), both bivariate and multivariate analyses suggest that older young persons (20-24 years old) enjoy more elastic freedom. This type of freedom allows them to participate more freely in the consumption of drugs than those younger (especially those under 14 years old) who may still be under the restriction of parents or guardians.

Male respondents who were presently schooling might have reported lower substance use owing to their awareness of possible side effects of such behaviour given that they benefit from various health promotion sensitisation programmes. It is also plausible to assume that a good proportion of in-school young persons should still be under the watchful supervision of their teachers and parents or guardians. Also, the schools present social environment where many anti-drug models are available and those caught in substance use are severely punished by the authorities. In the context of the social learning and differential association theories, therefore, young persons of lower age (for example under 14 years) and schooling presently are less likely to come in contact with or be over-exposed to drug users, as such less vulnerable to substance use behaviour (Bandura, 1971; Sutherland, 1947). Thus, young people aged 20-24 years old and out-of-school are more vulnerable to drug use (Baggio et al., 2015; Dada et al., 2016).

Furthermore, the fact that religiosity significantly predicted ever use of any unconventional drugs among males and not among females, in both bivariate and multivariate analysis, suggest that the influence of religiosity is stronger among males with respect unconventional drug use. The odds ratios indicate that those who were more religious were less likely to report ever use of any unconventional drugs. Young males that are more religious may not be as vulnerable to substance use as their less religious counterparts. Another way to explain the significant influence of religiosity among males could be that more religious young persons may not accept the need to feel high or strength derived from drugs for various nefarious activities or over-exposed to definitions favourable to unconventional drug use. It is also plausible to expect more religious young persons to observe more positive behaviours in their religious organisations that may serve as models or behavioural pattern to adopt (Bandura, 1977; Sutherland, 1947). So, such young people are less likely to adopt substance use because of poor attraction such behaviour may offer 
them and limited contact with drug users whose behaviour appear to legitimise drug use.

Moreover, it is not surprising that exposure to unconventional drugs through peer group significantly predicted ever use of any unconventional substance in both bivariate and multivariate statistical analysis. This finding is consistent with previous studies' report that peer group is a significant factors in adoption of drugs among young people (Dada et al., 2016). It is very plausible to state that young people who are exposed to drugs by their peers are also likely to be pressured to adopt drug consumption by such peers. Of course, in the contexts of social learning and differential association theories, frequent contact with such peers who may be substance use models can legitimise drug consumption. Consequently, young people may take to consumption of unconventional drugs (Cressey, 1952; McCarthy, 1996).

Although exposure to unconventional drugs through television was not significantly associated with ever use of the drugs in bivariate, there was statistically significant association between the two in multivariate analysis. First, this scenario suggests that exposure to drugs through television could only significantly predict ever use of any unconventional substance in the contexts of social, cultural, and demographic characteristics. Second, given that exposure to drugs through television exhibited a higher odds of ever use of any unconventional drugs, it suggests that visual display of drug users may present drug models to young people (Bandura, 1971). Also, young people frequent exposure to television models or drug users, may signal to them that unconventional drug use is a legitimate behaviour and consequently make them unconventional drug users (Cressey, 1952).

Concerning the implications of unconventional drug use among young people, the descriptive analysis showed that the indicators reflected an insightful association with unconventional drug use. First, the primary area of concern among males is the likelihood for young people who use the drugs to indulge in multiple sexual partnership. This finding supports previous studies that males who use drugs are more likely to be involved in multiple sexual partnership (Pillon et al., 2005). Although, they were also more likely to use STIs prevention strategies, multiple sexual partnership may still compromise their SRH. The situation is more pathetic among young females. Among those who indicated they ever used any unconventional drugs, though multiple sexual partnership was low, most did not report use of STIs prevention methods. The SRH situations observed among male and female respondents make this study consistent with previous investigations that have observed that drug use increases the risk of risky sexual health behaviours such as multiple sexual partnership and unprotected sex that opens door to STIs and unwanted pregnancy (Doku, 2012; Reid et al., 2015; Khadr et al., 2016, Janulis et al., 2018). These results suggest that the probability of unconventional drug use (as well as conventional drugs) increasing health burden in the study area was high (Degenhardt et al., 2016; Osman et al., 2016). Also, it appears young females 
are more vulnerable in this respect given the poor preventive behaviour among them.

\section{Conclusion}

Therefore, the results of the analysis support the study hypothesis that the social environment of young people is likely to influence their involvement in unconventional drug use. The social environment provided in the family through the frequency of interaction with mothers, schools, religious organisations, and exposure to unconventional drugs through peers and television, are critical factors in whether young people would take to unconventional drugs or not. Older young people, those out-of-school, being less religious, and exposed to unconventional substance use through peers and through television were more likely to report ever use of any unconventional substance. Tramadol, cough syrup, and rohypnol were the most popular unconventional substances ever used among both male and female respondents. Also, while young females who used various unconventional substances were vulnerable to STIs owing to poor preventive behaviour, multiple sexual partnership was rampant among their male counterparts though rich preventive culture prevailed among them. Thus, unconventional drug use among young people has a strong probability of increasing health burden through risky SRH in the study setting. Finally, social and development programmes focusing on drug use among young people should explore schools and religious institutions in addressing the menace of unconventional substance among them.

\section{References}

Baggio, S., Iglesias, K., Deline, S., Studer, J., Henchoz, Y., Mohler-Kuo, M., \& Gmel, G. (2015) Not in Education, Employment, or Training status among young Swiss men. Longitudinal associations with mental health and substance use. $J$ Adolesc Health, 56(2): 238-243, doi:10.1016/j.jadohealth .2014.09.006.

Baldwin, P., Shrestha, R., Potrepka, J. \& Copenhaver, M. (2013) The Age of Initiation of Drug Use and Sexual Behavior May Influence Subsequent HIV Risk Behavior: A Systematic Review. ISRN AIDS, 2013 (Article ID 976035), 17. doi:10.1155/2013/976035.

Bandura, A. (1971) Social Learning Theory. New York: General Learning Press.

Bleakley, H. (2010) Health, human, and development. Annual Review of Economics, 2: 283-310. doi:10.1146/annurev.economics.102.

Butler, K., Sindicich, N. \& Burns, L. (2014) Young people, drug use and risk behaviours. Australia: University of New South Wales.

Calsyn, D.A., Cousins, S.J., Hatch-Maillette, M.A., Forcehimes, A., Mandler, R., Doyle, S.R. \& Woody, G. (2010) Sex under the influence of drugs or alcohol: common for men in substance abuse treatment and associated with 
high risk sexual behaviour. American Journal of Addiction, 19(2): 119-127. doi:10.1111/j.1521-0391.2009.00022.x.

Cressey, D.R. (1952) Application and verification of the diffrential association theory. Journal of Criminal Law, Criminology, and Police Science, 43(1). Retrived from www.jstor.org/stable/i247672, 22 November 2018.

Dada, O., Odukoya, O. \& Okuyemi, K. (2016) Risk perception and correlates of alcohol use among out-of-school youth in motor parks in Lagos State, Nigeria. Malawi Medical Journal, 28(1). doi:10.4314/mmj.v28i1.5.

Degenhardt, L., Stockings, E., Patton, G., Hall, W.D. \& Lynskey, M. (2016) The increasing global health priority of substance use in young people. The Lancet Psychiatry, 3(3): 251-264. doi:10.1016/s2215-0366(15)00508-8.

Doku, D. (2012) Substance use and risky sexual behaviours among sexually experienced Ghanaian youth. BMC public health, 12(571): 1-7.

Fergusson, D.M., Boden, J.M. \& Horwood, L.J. (2015) Psychosocial sequelae of cannabis use and implications for policy: findings from the Christchurch Health and Development Study. Soc Psychiatry Psychiatr Epidemiol, 50(9): 1317-1326. doi:10.1007/s00127-015-1070-x.

Graves, K.L. \& Leigh, B.C. (1995) The relationship of substance use to sexual activity among young adults in the United States. Family Planning Perspectives, 27: 18-22 \& 33.

Haase, T. \& Pratschke, J. (2010) Risk and Protection Factors for Substance Use Among Young People: A Comparative Study of Early School-Leavers and School-Attending Students. Retrieved from Dublin: The Stationery Office.

Hall, W.D., Pathon, G., Stockings, E., Weler, M., Lynskey, M., Morley, K.I., \& Degenhardt, L. (2016) Why young people's substance use matters for global health. Lancet Psychiatriy, 3(3): 265-275.

Jackson, N.J., Isen, J.D., Khoddam, R., Irons, D., Tuvblad, C., Iacono, W.G., Baker, L.A. (2016) Impact of adolescent marijuana use on intelligence: Results from two longitudinal twin studies. Proc Natl Acad Sci USA, 113(5): E500-508. doi:10.1073/pnas.1516648113.

Janulis, P., Feinstein, B.A., Phillips, G., Newcomb, M.F. and Brain, M.B., (2018) Sexual partner typologies and association between drug use and sexual risk behaviour among men who have sex with men. Archieves of sexual behaviour, 47(1): 259-271.

Khadr, S.N., Jones, K.G., Mann, S., Hale, D., Johnson, R.A.M., Viner, R.M., Wellings, K. (2016) Investigating the relationship between substance use and sexual behaviour in young people in Britain: findings from a national probability survey. BMJ Open 2016;6:e011961. doi:10.1136/bmjopen2016-011961.

Macleod, J., Smith, G.D., Oakes, R., Copello, A., Crome, I., Egger, M., StokesLampard, H. (2004) Psychological and social sequelae of cannabis and other illicit drug use by young people: a systematic review of longitudinal, general population. The Lancet, 363(9421): 1579-1588. doi:10.1016/S01 40-6736(04)16200-4. 
McCarthy, B. (1996) The attitudes and actions: Tutelage and Sutherland's theory of differential association. British Journal of Criminology, 36(1): $135-147$.

Nwagu, N.E. (2015) Alcohol and drug usage and adolescent's sexual behaviour in Nigeria. Health Promotion International, 31: 405-413.

Olumide, A.O., Robinson, A.C., Levy, P.A., Mashimbye, L., Brahmbhatt, H., Lian, Q., Blum, R.W. (2014) Predictors of substance use among vulnerable adolescents in five cities: findings from the well-being of adolescents in vulnerable environments study. J Adolesc Healtdrinkh, 55(6 Suppl): S3947. doi:10.1016/j.jadohealth.2014.08.024.

Osman, T., Victor, C., Abdulmoneim, A., Mohammed, H., Abdalla, F., Ahmed, A., Mohammed, W. (2016) Epidemiology of Substance Use among University Students in Sudan. Journal of Addict, 1-8. doi:10.1155/ 2016/2476164.

Pillon, S.C., O’Brien, B. \& Chavez, K.A.P. (2005) The relationship between drugs use and risk behaviours in brazilian university students. Rev Latinoam Enfermagem, 13(número especial): 1169-1176.

Reid, J.L., Hammond, D., McCrory, C., Dubin, J.A. and Leatherdale, S.T. (2015) Use of caffeinated energy drinks among secondary school students in Ontario: Prevalence and correlates of using energy drinks and mixing with alcohol. Canadian Journal of Public Health, 106(3): e101-e108.

Schantz, K. (2012) Substance Use and Sexual Risk Taking in Adolescence. Retrieved from New York: www.actforyouth.net, 22 November 2018.

Stockings, E., Hall, W.D., Lynskey, M., Morley, K.I., Reavley, N., Strang, J., Degenhardt, L. (2016) Prevention, early intervention, harm reduction, and treatment of substance use in young people. The Lancet Psychiatry, 3(3): 280-296. doi:10.1016/s2215-0366(16)00002-x.

Sutherland, E.H. (1947) Principles of criminology. Philadephia: J. B. Lippincott Co.

Wells, B.E., Kelly, B.C., Rendina, H.J. \& Parsons, J.T. (2015) Prescription Drug Misuse and Sexual Behavior among Young Adults. Journal Sex Research, 52(6): 659-668. doi:10.1080/00224499.2014.918085. 